\title{
Habitat utilization by the giant water bug, Appasus (=Diplonychus) major (Hemiptera: Belostomatidae), in a traditional rice paddy water system in northern Osaka, central Japan
}

\author{
Yasuo MukaI and Minoru IsHII* \\ Entomological Laboratory, Graduate School of Agriculture and Biological Sciences, Osaka Prefecture University; Sakai 599-8531, \\ Japan
}

(Received 18 November 2006; Accepted 4 June 2007)

\begin{abstract}
To elucidate the seasonal pattern of habitat utilization by Appasus (=Diplonychus) major, a mark and recapture census was carried out. We categorized ten bodies of water for investigation into five categories: permanent pool, temporary pool, ditch, paddy and marsh, according to the water regime and vegetation structure. A total of 1,143 adults were marked, and 383 (34\%) were recaptured more than once during the study period. Adults marked in June were recaptured in the same or the following month, while those marked between July and December were recaptured until the following July. The results show that $A$. major has a univoltine life cycle at the study site, overwintered adults reproduce in June and July, and adults of the new generation appear from July. Adults and nymphs of all instars were observed in all five types of waters, and the density was high in the ditch. Overwintering adults were observed on the moist ground of the drained paddy as well as in the water of the ditch. Overwintering adults had the ability to walk around and forage even in winter. A total of 50 movements of adults were observed among different types of waters, and adult movement was most frequent between April and July. The existence of different types of waters in the traditional rice paddy water system such as the study site was favorable for maintaining the population of $A$. major.
\end{abstract}

Key words: Giant water bug; Appasus (=Diplonychus) major; paddy; mark and recapture census; overwintering site

\section{INTRODUCTION}

The traditional rice paddy water system, which consists of paddies, ditches, irrigation ponds and abandoned or fallow paddies, has long provided wild animals and plants with a variety of habitats (e.g. Moriyama, 1997; Kiritani, 2000; Lawler, 2001; Takeuchi et al., 2003); however, the species diversity in these systems has been declining due to recent land consolidation, modification of traditional earth ditches to U-shaped concrete ditches and the use of agricultural chemicals such as insecticides and herbicides in Japan (Moriyama, 1997; Kadono, 1998; Udagawa, 1998; Kiritani, 2000).

Since many paddy fields have been made by modification of natural wetlands (Kiritani, 2000; Lawler, 2001), the rice paddy water system is considered to be an important alternative habitat for species originating in natural wetlands (Moriyama,
1997). About one fifth of the threatened insect species listed on the Red Data List of Japan (Ministry of the Environment of Japan, 2006) are considered to be wetland-associated species, and include diving beetles such as Cybister species, and belostomatid bugs such as Lethocerus and Appasus species (Ishii, 2003). Most natural wetlands have disappeared or been degraded in Japan, so that currently, many aquatic organisms inevitably depend partly or fully on the paddies (e.g. Moriyama, 1997; Hasegawa, 1998; Ueda, 1998; Kiritani, 2000). Even though paddies cannot completely substitute natural temporary ponds, they are important habitats for sustaining aquatic organisms (Lawler, 2001).

During the past few decades, studies focusing on the conservation of aquatic animals including aquatic insects (Hibi, 1994; Hidaka, 2000; Ichikawa, 2004), frogs (Fujioka and Lane, 1997; Hirai and

\footnotetext{
* To whom correspondence should be addressed at: E-mail: ishii_m@envi.osakafu-u.ac.jp DOI: $10.1303 / \mathrm{aez} .2007 .595$
} 
Matsui, 2001), waterbirds (Fasola et al., 1996; Marques and Vicente, 1999) and fishes (Katano, 1998) inhabiting rice paddy water systems have been conducted. Topics such as the life cycle of Sympetrum dragonflies (Ueda, 1998), food preferences of nepids and belostomatids (Okada and Nakasuji, 1993a; Hirai and Hidaka, 2002; Ohba and Nakasuji, 2006), the interspecific relationship between two closely related belostomatine water bugs (Okada et al., 1992), and the factors affecting the induction of flight behavior in a lethocerine water bug (Ohba and Takagi, 2005) have been studied thus far with respect to lentic insects. Studies on seasonal habitat utilization by several aquatic insects in rice paddy water systems have also been conducted, and some authors have pointed out that a habitat mosaic in and around the water system would be necessary for aquatic insects to thrive (Hibi, 1994; Ueda, 1998; Saijo, 2001).

The belostomatine water bug, Appasus major, inhabits shallow waters in mountainous regions including the traditional rice paddy water system (Ichikawa, 1996). Saijo (2001, 2002) reported that this species utilizes irrigation ponds, paddies and fishponds as habitats in a rice cultivation area among mountains in western Honshu, Japan. This species, like the other aquatic insects inhabiting paddy systems, is declining in many regions in Japan, and is designated as a red data list species in Osaka Prefecture (Osaka Prefecture, 2000); however, few studies on population dynamics in the traditional rice paddy water system have been carried out for conservation of this species.

In this study, to elucidate the seasonal pattern of habitat utilization and factors affecting the population dynamics of $A$. major, a mark and recapture census was carried out in a traditional rice paddy water system in the mountains of northern Osaka Prefecture, central Japan. We discuss the relationship between the life cycle of $A$. major and both water management and the arrangement of water in the rice paddy water system for conservation of the species in the system.

\section{STUDY SITE}

This study was carried out in the upper part of a rice terrace in a traditional rice paddy water system in Nagatani (alt. ca. $350 \mathrm{~m}$ ), located among moun- tains in Nose town, northern Osaka Prefecture, central Japan from June, 2000 to December, 2001 (Fig. 1). The water system was dependent on spring water from a special irrigation system called 'Gama', a pipeline system made of stones underground. The study site was comprised of ten bodies of water, which were categorized into five types based on the patterns of water management and vegetation structure as follows: two paddies, Pad$\operatorname{dies} \mathrm{A}$ and $\mathrm{B}$, three permanent pools, Pools A, C and $\mathrm{D}$, a temporary pool, Pool B, three ditches, Ditches A, B and C, and a Marsh. The permanent and temporary pools were made for the study using fallow paddies. The paddies and temporary pool were irrigated in late April and drained from late September to the following April, following the patterns in the surrounding paddies in the rice terrace. The permanent pools, Pools $\mathrm{A}, \mathrm{C}$ and $\mathrm{D}$, were kept flooded with about 15,5 , and $20 \mathrm{~cm}$ of water, respectively, throughout the year. The ditches were narrow-shaped permanent water systems with seasonal water fluctuation that was synchronous with the water management of the paddies, and had the function to warm the spring water from the 'Gama' before the water flowed into the paddy. In the ditch, the water depth fluctuated seasonally, being deep during the irrigation period of the paddies but shallow during the drainage period. The Marsh, an abandoned paddy into which spring water continuously flowed throughout the year, was a body of water with short dense vegetation dominated by the swamp millet, Isachne globosa (Gramineae). No agricultural chemicals such as insecticides and herbicides were used at the study site during the study period.

Air temperature at about $1.5 \mathrm{~m}$ above ground in the shade near the Marsh and water temperatures in each body of water were recorded in censuses using maximum and minimum thermometers (Maximum \& Minimum thermometer, Nihon Keiryoki Kogyo Co., Ltd., Japan). The environment and vegetation structure in and around the waters, and agricultural regimes, such as water management performed in and around the site, were described in detail in Mukai et al. (2005).

\section{METHODS}

Population dynamics. To elucidate the population dynamics including the pattern of seasonal 


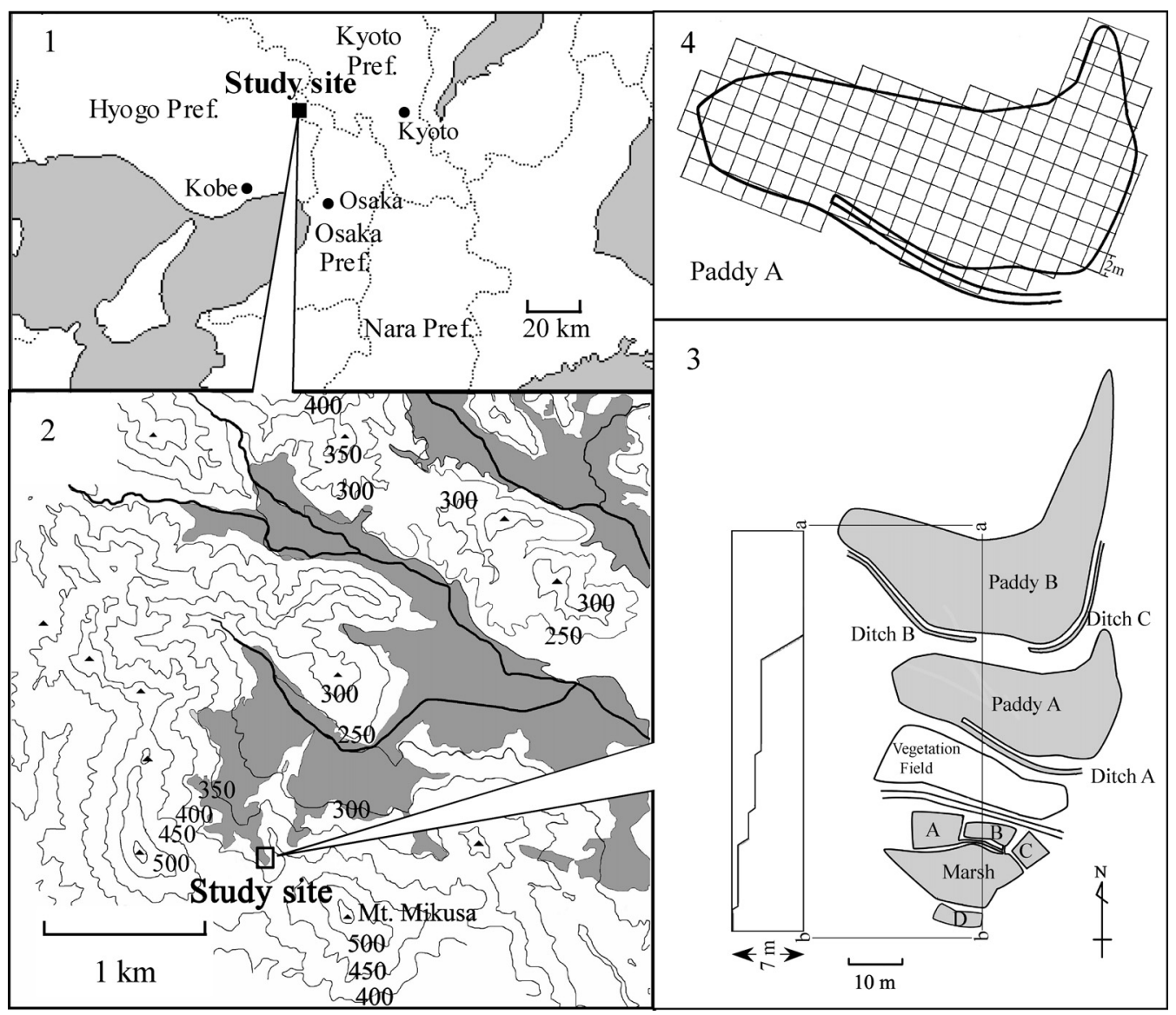

Fig. 1. Location of the study site (1,2), arrangement of 10 subsites (3) and quadrats investigated in February and March, 2001 (4) in Nagatani, Nose town, northern Osaka Prefecture, central Japan. Shading indicates the rice cultivation area (2). A, B, C and D indicate Pools A, B, C and D, respectively, and the left figure on the map indicates a cross section of the site along the line from a to $b(3)$.

habitat utilization, a mark and recapture census of A. major adults was carried out once a week as a rule from June, 2000 to December, 2001. Adults and nymphs were captured in the water within $1.5 \mathrm{~m}$ from the edge in the paddies, and throughout the body of water in the other waters by sweeping a D-frame dip net $(40-\mathrm{cm}$ in width and $1-\mathrm{mm}$ in mesh size) along the bottom. Newly captured adults were numbered individually on their forewing, pronotum and abdomen using a black felt pen (YK, Sakura Color Products Co., Ltd., Japan). Individual number and sex of adults, and the numbers of nymphs in early (1st and $2 \mathrm{nd}$ ), middle (3rd and 4th) and final (5th) instars were recorded, and the bugs were released in the respective water from which they had been caught. Nymphal density was estimated by the sweeping method. The number of encumbered males was also recorded in 2001. In the paddies, sweeping was not conducted from
September because the water depth gradually decreased and became too shallow to sweep during the month. The population size of adults was estimated using the Chapman modification of the Petersen method (Chapman, 1951) from June, 2000 to April, 2001 in Pool B, Ditch A, Paddy A and Marsh where more than 10 adults had been captured during the period. Densities of adults and nymphs were compared among all types of waters using the paired $t$-test with sequential Bonferroni correction (Rice, 1989) in the periods from June to August, 2000 and from May to August, 2001.

Prey density. We selected larvae of libellulids, dipterans and corixids as possible prey according to Okada and Nakasuji (1993a), and estimated their density by the sweeping method in Paddy A, Pools A and B and Ditch A from April to December in 2001, and in the Marsh from May to December in 1999. 
Overwintering in a drained paddy. Since two overwintering adults were found in the soil of the levee of Paddy A in a preliminary survey in late November, 2000, an investigation was carried out in and around Paddy A to elucidate the microdistribution and survival of overwintering adults from December, 2000 to March, 2001. We conducted surveys of overwintering adults in a $124-\mathrm{m}^{2}$ area of Paddy A and its levee on December 7, 2000 and January 11,2001 . We also carried out surveys from January 31 to February 22 (February survey) and from March 5 to 26 (March survey) in 2001, respectively. In the February and March surveys, we set $1694-\mathrm{m}^{2}$ quadrats $(2 \mathrm{~m} \times 2 \mathrm{~m})$ in Paddy $\mathrm{A}$ and its levee (Fig. 1), and conducted investigations on the microdistribution of overwintering adults. Newly captured adults were numbered using the method described above, and the individual number, sex and microhabitat where the bug was found were recorded before it was released. Individuals showing any movement were regarded as living. Distribution patterns of overwintering adults were analyzed using Morisita's $I_{\delta}$ index (Morisita, 1962).

We recorded temperatures of air, water and the soil of the drained paddy from October, 2004 to March, 2005, as we failed to record them in the winter of 2000 and 2001. The pattern of seasonal change in air temperature in Nose town was similar from 2001 to 2005 according to the Japanese Meteorological Agency. Temperatures of water, air in the shade at $1.5 \mathrm{~m}$ above ground and of the soil at a depth of $4 \mathrm{~cm}$ and $10 \mathrm{~cm}$ in Paddy A were recorded at intervals of $60 \mathrm{~min}$ using data loggers (Thermochron I-Buttons Dallas Semiconductors, Dallas, Texas) from October, 2004 to March, 2005.

\section{RESULTS}

\section{Population dynamics}

A total of 1,143 adults were numbered and 383 (34\%) were recaptured more than once from June, 2000, to December, 2001. Of 28 adults marked in June, 2000, 5 and 1 were recaptured in the same and the following month, respectively, while 191 of 413 adults marked between July and December, 2000 were recaptured more than once until the following July irrespective of the month of marking (Fig. 2). The results show that A. major has a univoltine life cycle at the study site, overwintered

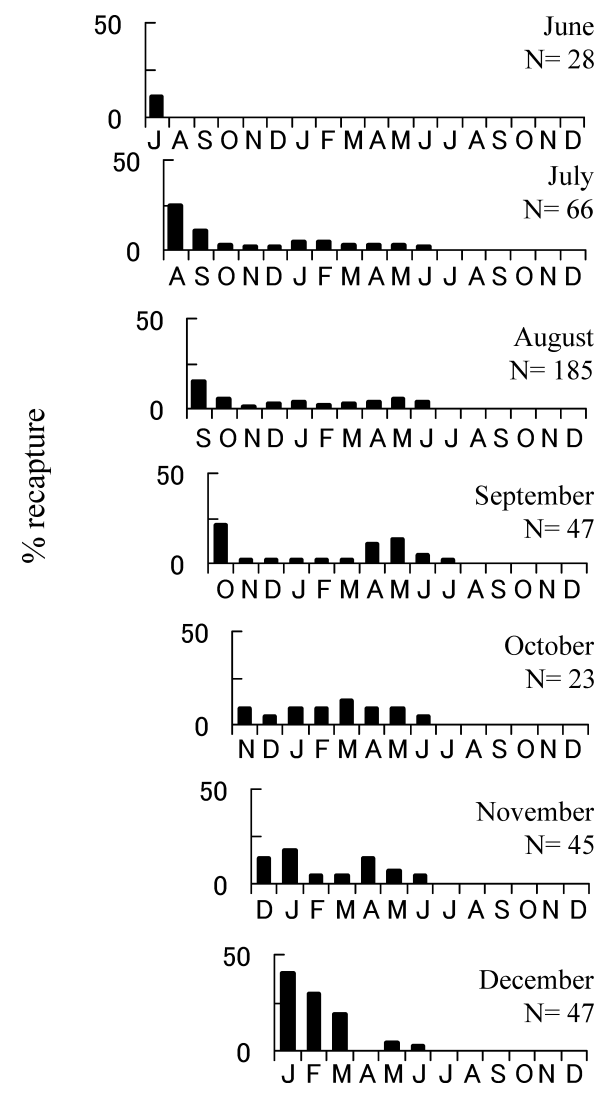

Fig. 2. Monthly changes in the percentage of recaptured adults in $A$. major marked at the study site from June to December, 2000.

adults reproduce in June and July, and adults of the new generation appear from July.

Adults were observed in all types of waters. The density of adults was highest in the ditch in 2001, while it was not different significantly among all types of waters in 2000 (Fig. 3 and Table 1). Adults disappeared from the permanent and temporary pools and the Marsh before February, while they were continuously observed in the ditch throughout the year. In the paddy, adult density was low during the irrigation period, but many adults were found on the soil from December to March, as described below. Adult density decreased in the paddy in May.

The pattern of seasonal change in the estimated population size of adults was similar to that in adult density (Fig. 4). The adult population size showed a peak of 303 individuals in late August for the entire study site, while it was estimated as about 20 individuals in winter. The estimated population size was largest in Paddy A with a peak of about 150 individuals at the end of the irrigation 


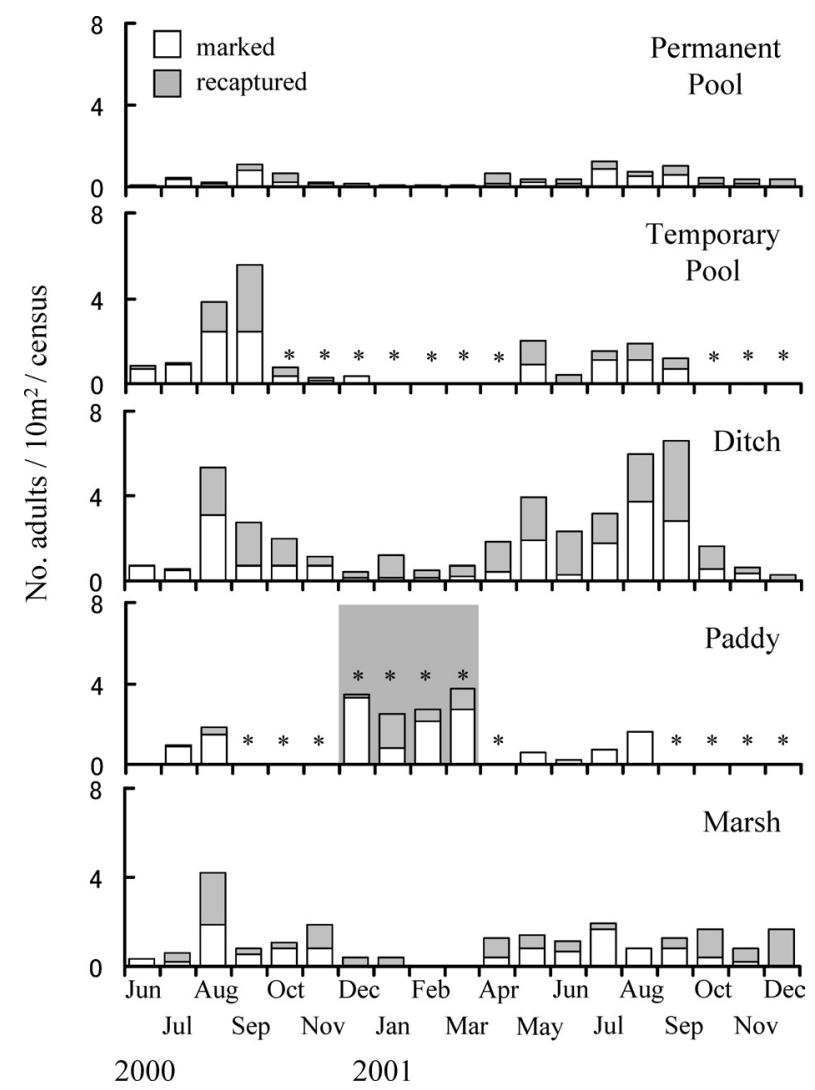

Fig. 3. Seasonal changes in the number of $A$. major adults per $10 \mathrm{~m}^{2}$ captured in five types of waters at the study site from June, 2000 to December, 2001. Columns in shaded area indicate the number of adults on the soil of a drained paddy. * Drainage period.

Table 1. Differences in density of adults among all types of waters during the irrigation period of the paddies in 2001

\begin{tabular}{lccccc}
\hline & Perm. & Temp. & Ditch & Paddy & Marsh \\
\hline Perm. & - & & & & \\
Temp. & NS & - & & & \\
Ditch & $* *$ & $* *$ & - & & \\
Paddy & NS & NS & $* *$ & - & \\
Marsh & NS & NS & $* *$ & NS & - \\
\hline
\end{tabular}

Densities were compared using paired $t$-test.

Perm., permanent pool; Temp., temporary pool.

$* *, p<0.01$ (Sequential Bonferroni adjusted probability).

period, late August.

Encumbered males were observed at the study site from April to August, but they appeared about one month earlier in the ditch and permanent pool than in the paddy in 2001 (Fig. 5); however, early instar nymphs appeared simultaneously in late June in all types of waters in both years. Nymphs of all

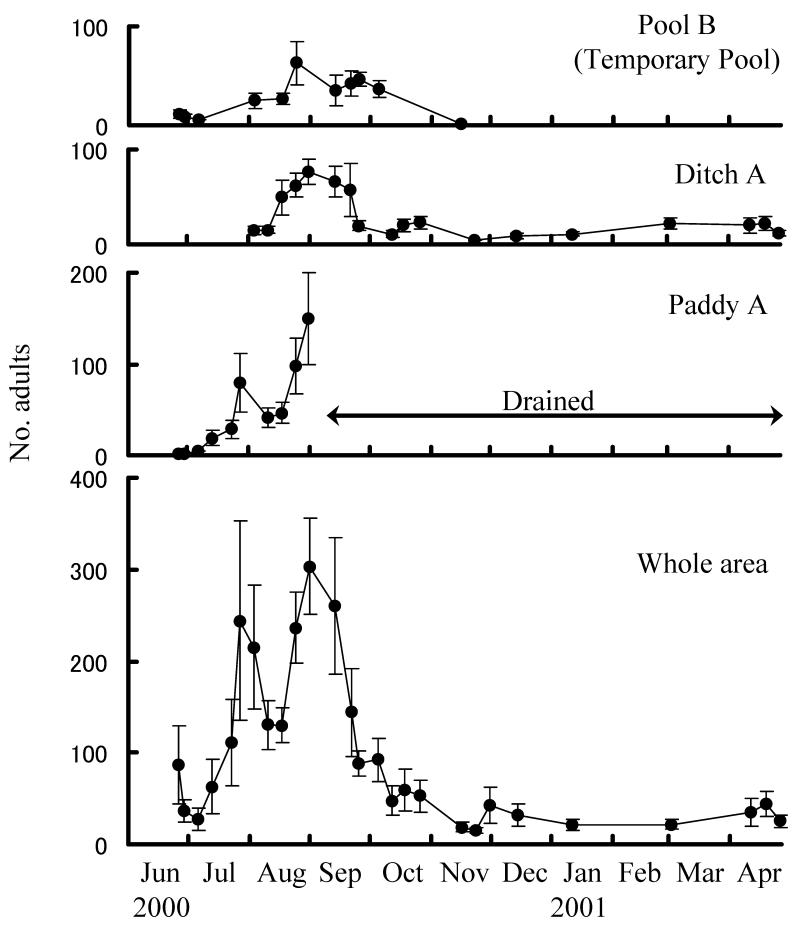

Fig. 4. Seasonal changes in population sizes of $A$. major adults in water estimated using the Chapman modification of the Petersen method (Chapman, 1951). Vertical lines indicate the standard deviation for each estimation.

instars were found in all types of waters from late June to September. The density of nymphs was significantly lower in the permanent pool than in the other types of waters except the paddy in 2000 , and it was highest in the ditch, as in adults, in 2001. The results show that $A$. major utilizes all types of waters as reproduction sites from June to September, and no nymphs pass the winter at the study site.

\section{Prey density}

Possible insect prey belonging to three groups, larvae and/or adults of dipterans (Chironomidae spp., Tipulidae sp. and Culicidae spp.), libellulids (Sympetrum spp., Orthetrum spp. and Crocothemis servilia) and corixids (Sigara sp. and Micronecta sp.), were observed in the permanent and temporary pools, ditch and Marsh through the year with a peak density in July or August, while they were found during the irrigation period in Paddy A (Fig. 6). Larvae of dipterans were observed in spring and autumn, while corixids were dominant in July and August. Libellulid larvae were seen throughout the year with a small peak in September or October. 

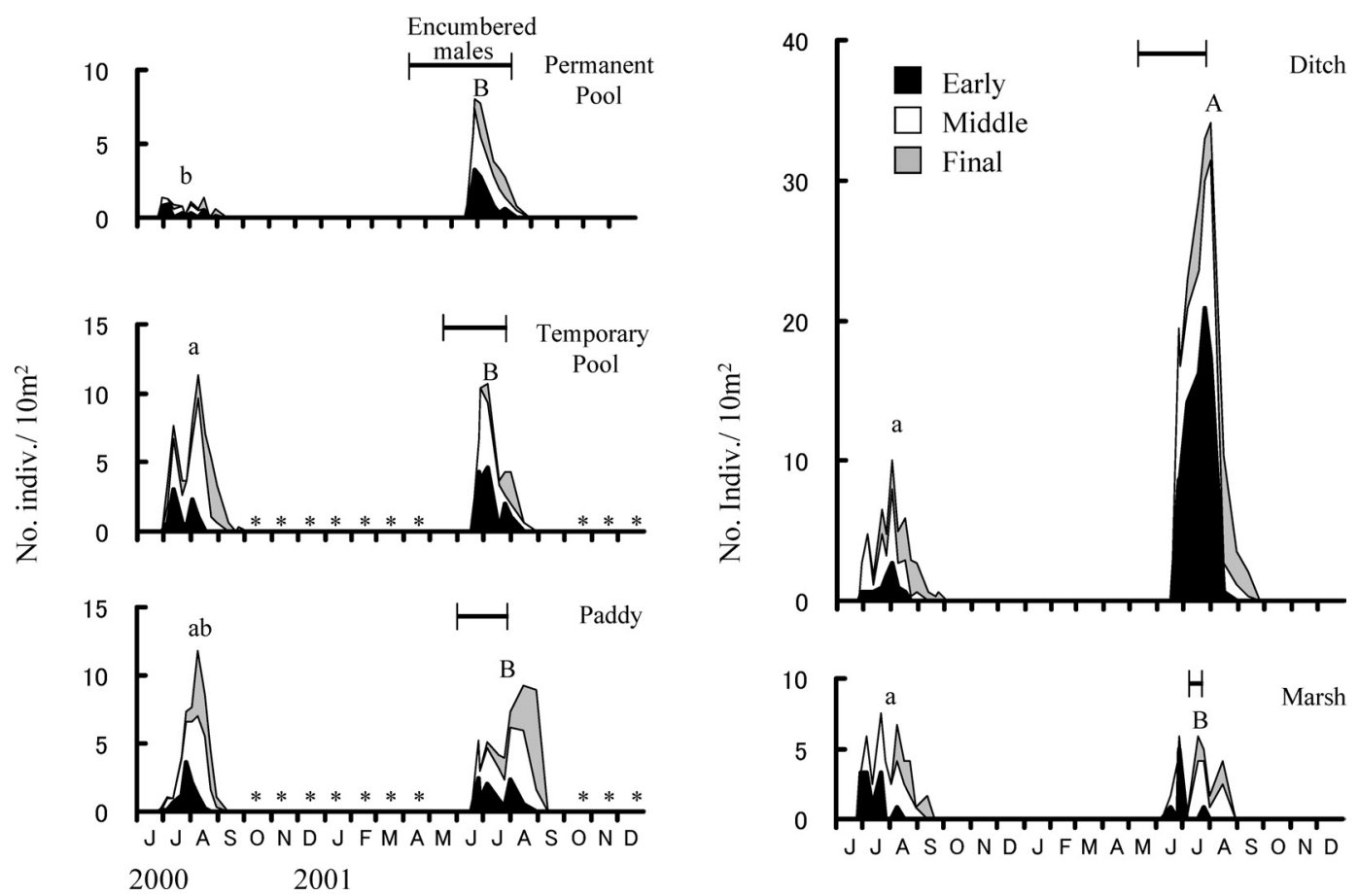

Fig. 5. Seasonal changes in the number of A. major nymphs of early (1st and 2nd), middle (3rd and 4th) and final (5th) instars per $10 \mathrm{~m}^{2}$ captured in five types of waters at the study site from June, 2000 to December, 2001. Horizontal bar on the upper graph in each water type indicates the period from first to last observation of encumbered males. * Drainage period. Densities of nymphs during the irrigation period of the paddies, with different letters for each year, are significantly different (paired $t$-test with sequential Bonferroni correction, $p<0.05)$.

\section{Overwintering in a drained paddy}

A total of 64 overwintering adults were found on the ground of Paddy A and its levee on December 7, 2000 and the number of adults decreased to 26 on January 11, 2001. A male was found to have moved about $1.5 \mathrm{~m}$ between the two observations. The results demonstrate that adults of $A$. major utilize drained paddies as one of their overwintering sites at the study site, and that they have the ability to move on land.

A total of 186 and 256 overwintering adults were recorded from 70 and 82 of the 169 quadrats in the February and March surveys, respectively. The mean density of overwintering adults was 2.8 and 3.8 (individuals $/ 10 \mathrm{~m}^{2}$ ) in both surveys, respectively, and the values were much higher than those in the ditch and Marsh (0.69 and 0.21 on average, respectively, during winter, see Fig. 3). The soil of the drained Paddy A remained wet due to spring water from the Gama during the drained period, and the ground surface was sparsely covered with fallen dead plants such as the rice plant, Oryza sativa (Gramineae) and the hygrophyte, Monocho- ria vaginalis (Pontederiaceae), with coverage being thick in the western part. There were many footprints of the wild boar, Sus scrofa, and the sika deer, Cervus nippon, throughout the area of Paddy A. Most adults were found in small pits of the footprints and beneath the fallen dead plants, while a few were found under soil clusters, in puddles, and on bare ground exposed directly to the air in the two surveys (Fig. 7). A large portion of overwintering adults was found in quadrats on the west side of Paddy A, and their distribution was significantly contiguous in both the February $\left(n=186, I_{\delta}=3.18\right.$, $p<0.05)$ and March surveys $\left(n=256, I_{\delta}=2.75\right.$, $p<0.05)$. Nine $(4.8 \%)$ and $18(7.0 \%)$, including all 6 and 11 adults on the bare ground directly exposed to the air, were found dead in the February and March surveys, respectively (Fig. 7). Twenty adults were found to move 5 to $600 \mathrm{~cm}$ between the two surveys (Fig. 8). It should be noted that two overwintering adults were observed preying on larval tipulid and blattellid on the ground of Paddy A in the March survey. These results demonstrate that overwintering adults of $A$. major have the ability to 


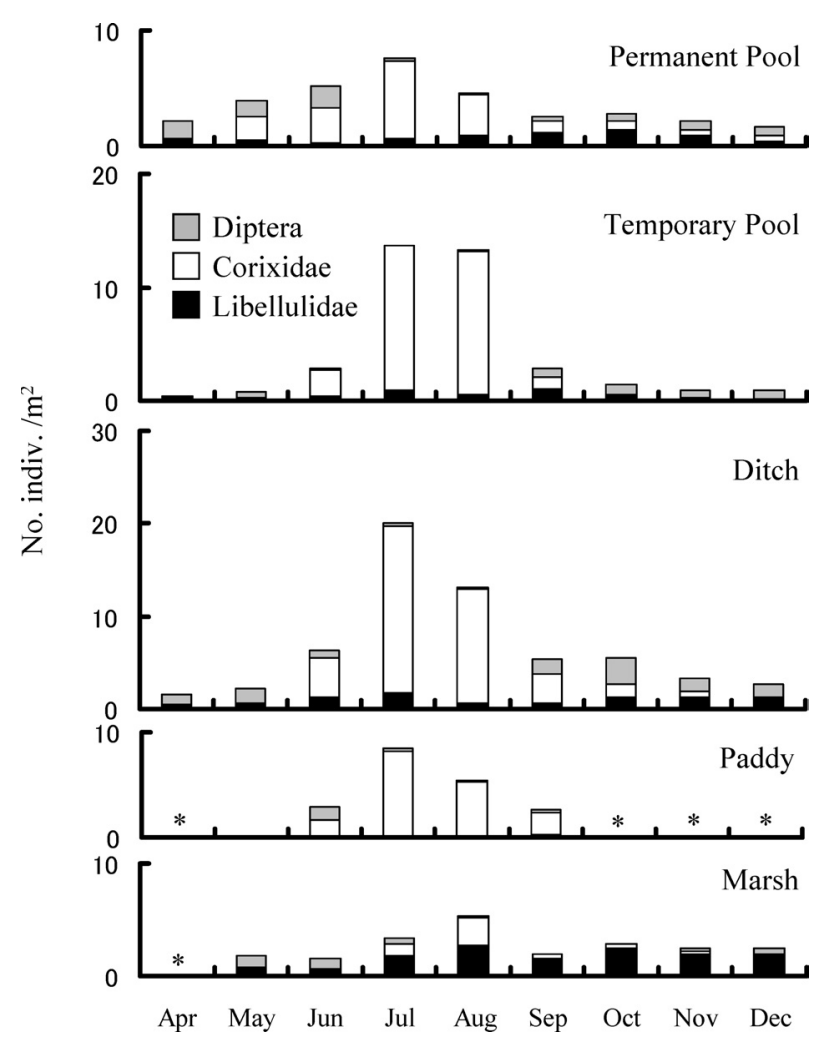

Fig. 6. Seasonal changes in densities of possible prey organisms of $A$. major, larvae of libellulids and dipterans and corixids in the Marsh and the other types of water, from April to December in 1999 and 2001, respectively. * Months without investigation.

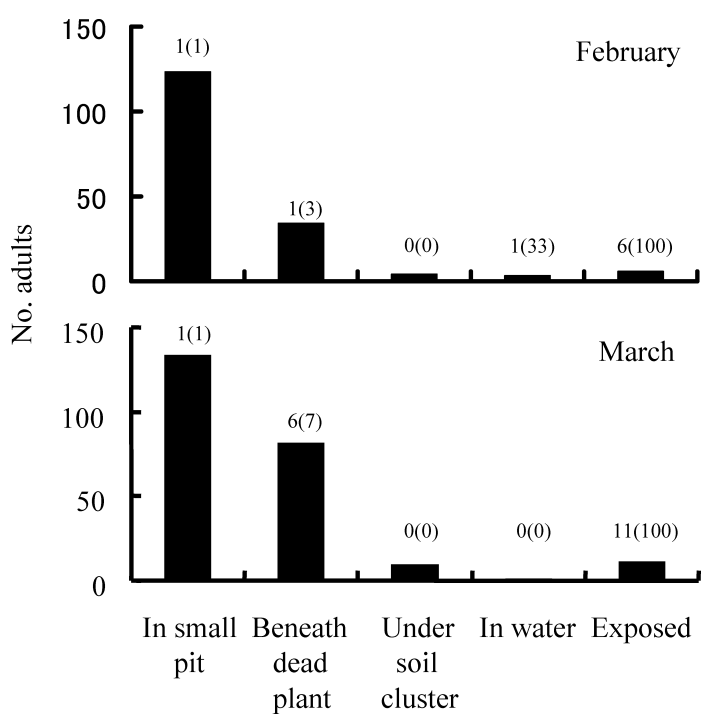

Fig. 7. Number of A. major adults observed in each microenvironment in drained Paddy A at the study site in February and March surveys in 2001. Numerals above each column indicate the number of dead adults (\%) among the total number of adults observed in each microenvironment. Rates of individuals utilizing each type of microenvironment are significantly different between February and March $\left(\mathrm{df}=4, \chi^{2}=13.9, p<0.01\right)$.

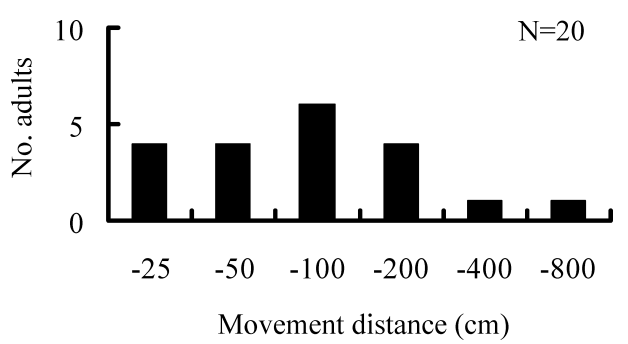

Fig. 8. Frequency distribution of the distances that adults of A. major moved on a drained paddy and its levee between February and March, 2001

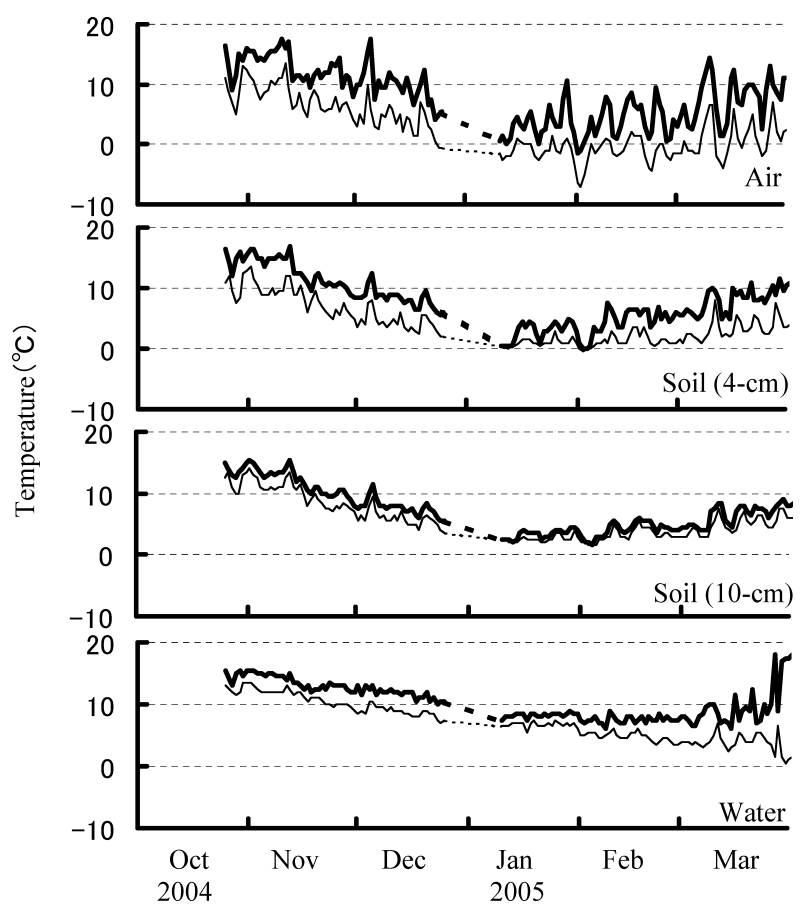

Fig. 9. Seasonal changes in daily maximum (thick line) and minimum (thin line) temperatures of air at $1.5 \mathrm{~m}$ above ground in shade (upper), at 4-cm soil depth in the drained paddy (middle upper), at 10-cm soil depth (middle lower) and of water in the ditch (lower) at the study site from late October, 2004 to late March, 2005.

walk around and forage on the ground of a drained paddy even in the winter.

At the study site, daily minimum air temperature often fell below $0^{\circ} \mathrm{C}$ from December to March, and the lowest air temperature reached $-7^{\circ} \mathrm{C}$ in early February (Fig. 9). In contrast, the daily minimum temperature of water in the ditch and that of soil in the ground of Paddy A rarely fell below $0^{\circ} \mathrm{C}$ and the fluctuations were small compared with those of the air temperature. The results show that temperatures in the water and the soil of the drained paddy are higher and more stable than those of the ground 

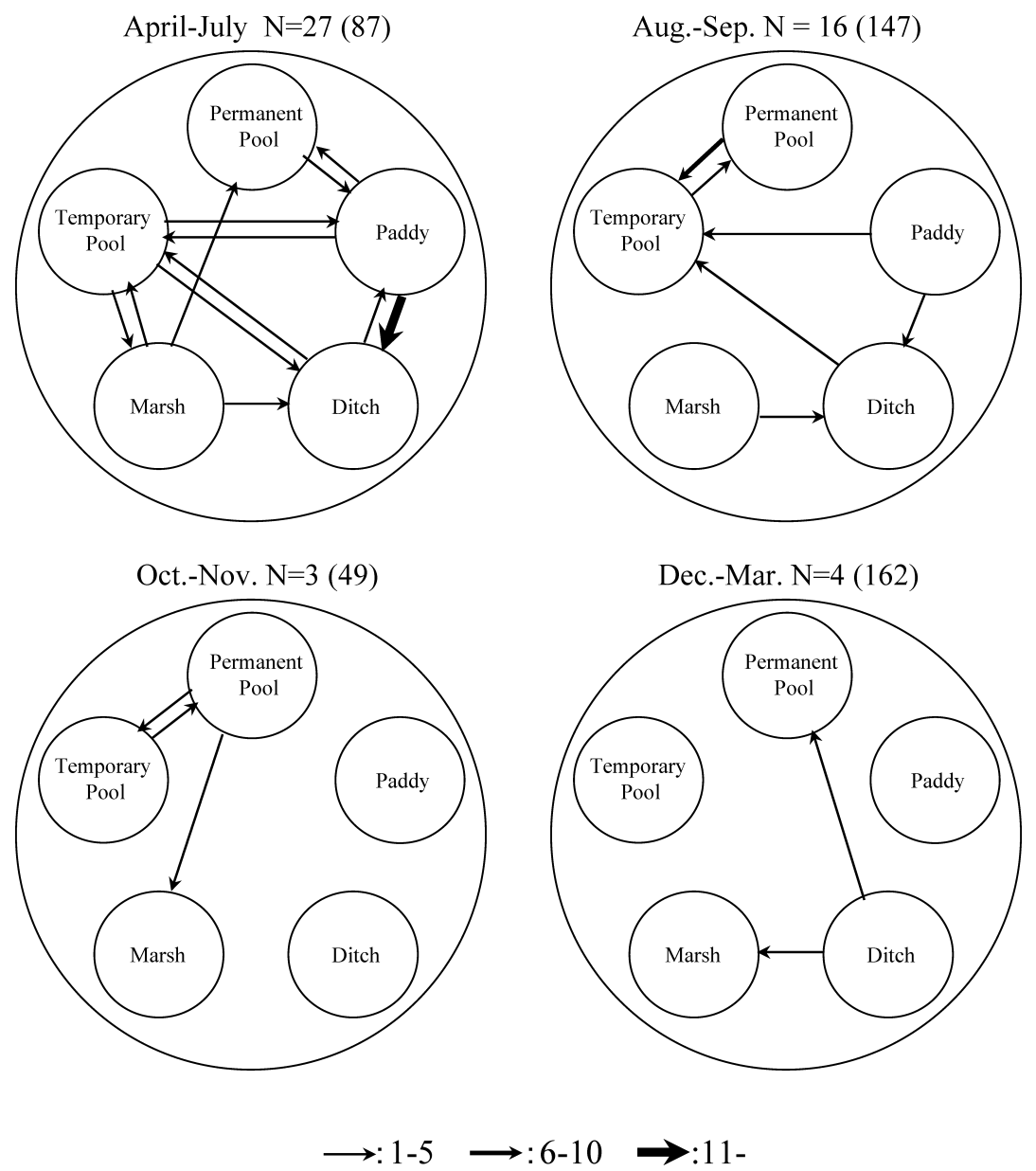

Fig. 10. Frequency and direction of seasonal movement of adults of $A$. major among five types of waters at the study site from June, 2000 to May, 2001. Arrow thickness indicates the frequency of movement in each season. Numerals on each graph indicate the number of adults that moved toward different types of waters, with the total number of adults recaptured in each period in parentheses.

surface exposed directly to the air.

\section{Seasonal movements}

Fifty movements of adults were observed among different types of waters from June, 2000 to May, 2001 (Fig. 10). Adults moved most frequently between April and July among all types of waters, and it should be noted that as many as 12 adults were recorded to move from the paddy to the ditch in this season. The frequency of adult movement was second highest in August and September, and there was some tendency to move toward the temporary pool. Adult movement among different types of waters was less frequent from October to March.

\section{DISCUSSION}

Our results revealed that $A$. major at the study site maintains its population by utilizing a variety of waters in the paddy system as its habitat. At the study site, this species has a univoltine life cycle, with encumbered males and nymphs being observed from April to September (Fig. 5); adults were also seen in the water during non-reproductive seasons (see Figs. 2 and 3). The irrigation period of paddies was restricted from May to September, but the ditches were kept flooded throughout the year. It was favorable for the reproduction of $A$. major that paddies in the study site were continuously kept flooded during the irrigation period, unlike the situation in many other paddies in Japan where midseason drainage and/or intermittent irri- 
gation are usually performed in mid-summer (Hidaka, 1998). Our study also showed that A. major utilizes drained paddies as one of its overwintering sites at the study site.

The life cycle of A. major is reported to be univoltine with reproduction occurring around summer in other paddy systems in Japan (Okada and Nakasuji, 1993a; Ichikawa, 1996), although no comparison of population dynamics among different types of waters in the system was carried out. The results of this study showed that the intensity of habitat utilization by $A$. major differed among the various types of waters (Fig. 3). Although adults and nymphs of $A$. major were observed in all types of waters at the study site, density was high in the ditch from May to August (Table 1, Figs. 3 and 5). In the other belostomatid lethocerine, Lethocerus deyrolli, high prey density, high water temperature and available oviposition substrata were considered as important factors affecting the density in different types of waters in the paddy system (Mukai et al., 2005). This study showed that prey density was also among the important factors affecting the density of $A$. major. The density of $A$. major was high in waters where aquatic insects such as nymphs of libellulids, and adults and nymphs of corixids were abundant, while the density of $L$. deyrolli was affected by that of tadpoles and frogs (Mukai et al., 2005). Okada and Nakasuji (1993a) reported that libellulid larvae are among the possible prey of $A$. major in the rice paddy water systems in Okayama Prefecture, western Japan.

Regarding the water temperature, Okada and Nakasuji (1993b) reported that A. major prefers waters of lower temperature than the congeneric species, A. japonicus. Indeed, A. major was found reproducing in all types of waters including the Marsh, where the water temperature was always lower than in other waters at the study site in the reproductive season in A. major. Mukai et al. (2005) pointed out that $L$. deyrolli do not utilize the Marsh for reproduction, probably because of the low water temperature, low density of possible prey and absence of suitable oviposition substrata. Females of $L$. deyrolli lay eggs on substrata such as culms of aquatic plants, while belostomatine bugs such as $A$. major, whose females lay eggs on the back of male adults, need no substrata for oviposition. It is possible that this is one reason why
A. major utilizes a wider range of waters than $L$. deyrolli in the paddy system.

Our study revealed that $A$. major adults pass the winter in both aquatic and terrestrial habitats. At the study site, A. major utilized the ditch and drained paddy as overwintering sites, and the density of adults was higher from December to March on the ground of the drained paddy than in the ditch water (Fig. 3). Since paddies are the largest bodies of water in the water system of rice paddies, they are considered as the most important habitat for overwintering, as well as for reproduction. In this study, the population size was estimated to be largest in Paddy A, especially at the end of the irrigation period, late August (Fig. 4), as it had the largest area despite a lower density than the ditch and temporary pool. In Paddy A, middle and final instar nymphs were observed in late August (Fig. 5 ), and many adults were found from December to March; thus, it is possible that new adults continuously emerged in Paddy A until the water was completely drained at the end of September.

However, overwintering on land in the paddy may be risky for adults of $A$. major, as the temperature of the soil surface can fall below that of air in winter (Bale et al., 1988). Frisbie and Lee (1997) reported that adults of a belostomatid, Belostoma flumineum, survived $24 \mathrm{~h}$ exposure to $-4^{\circ} \mathrm{C}$ when supercooled, but they can not survive when frozen. Considering that all the adults of $A$. major on the bare ground directly exposed to the air were found dead in this study (Fig. 7), the cold hardiness of A. major is inferred to be as weak as that of $B$. flumineum. In $A$. major, most adults passed the winter in small pits where the soil temperature was warm and stable compared with the atmospheric temperature at the study site (Figs. 7 and 9). In addition, adults have the ability to move on land even in the winter, so that the proportion of utilization of each microenvironment changed during the winter (Figs. 7 and 8). It is likely that adults of $A$. major passing the winter on the surface of a drained paddy avoid the risk of freezing to death by selecting suitable microenvironments during the winter; however, puddling in preparation for rice transplanting in the spring may have a strong impact on adults overwintering in drained paddies. Further studies are needed to estimate the cold hardiness and the impact of puddling on adults.

Saijo (2001) categorized A. major into a group 
of aquatic insects living in both paddies and irrigation ponds, and reproducing mainly in paddies, according to an investigation in a paddy water system. However, the results of our study demonstrate that both paddies and ditches are among the habitats essential for A. major to complete its life cycle, including overwintering at the study site, although other types of waters are also used for reproduction from April to August. Adult movement was frequently observed among all types of waters during the reproductive season from April to September at the study site (Fig. 10); however, it is unclear whether adults of $A$. major dispersed by flight or by walking. In the case of $L$. deyrolli, older nymphs are able to disperse to neighboring waters beyond the levee by walking (Mukai et al., 2005). Lytle (1999) reported that adults and older nymphs of a belostomatine water bug, Abedus herberti, walk away on land from the stream to avoid flash floods as a response against heavy rainfall. Saijo (2001) noted that $A$. major adults are often observed on the wet banks of an irrigation pond. In any case, $A$. major utilizes a variety of waters in the rice paddy system by active movement to maintain their population. The existence of different types of waters in the traditional rice paddy water system, as at the study site, was favorable for maintaining the population of A. major.

In this study, nymphs of $A$. major appeared from late June synchronously in all types of waters, though encumbered males were observed earlier in permanent waters such as the permanent pool and ditch (Fig. 5); thus, midseason drainage and/or intermittent irrigation should have a large impact on the population dynamics of the species. In addition, land consolidation, which is the conversion of poorly drained paddy into well-drained dry paddy using a below-ground drainage system, tillage in winter, winter cropping and conversion to conventional water management will have a large impact on the population dynamics of A. major. Poorly drained paddies such as at the study site, which are wet in winter and kept flooded throughout summer, are suitable to support the entire life cycle of $A$. major.

\section{ACKNOWLEDGEMENTS}

We express our sincere thanks to members of the Nature Conservation Society of Osaka for their helpful cooperation. We also thank Dr. T. Hirowatari and Dr. N. Hirai, Entomologi- cal Laboratory of Osaka Prefecture University, for invaluable comments and advice. Our thanks are also due to our colleagues in the laboratory for their helpful cooperation and comments. This research was supported by Grants-in-Aid from the Nippon Foundation (1999 and 2000), and from the Ministry of Education, Culture, Sports, Science and Technology of Japan (no. 15510193).

\section{REFERENCES}

Bale, J. S., R. Harrington and M. S. Clough (1988) Low temperature mortality of the peach-potato aphid Myzus persicae. Ecol. Entomol. 13: 121-129.

Chapman, D. G. (1951) Some properties of the hypergeometric distribution with applications to zoological censuses. Univ. California Public. Stat. 1: 131-160.

Fasola, M., L. Canova and N. Saino (1996) Rice fields support a large portion of herons breeding in the Mediterranean region. Colonial Waterbirds (Special Publication 1) $19: 129-134$.

Frisbie, M. P. and R. E. Lee (1997) Inoculative freezing and the problem of winter survival for freshwater macroinvertebrates. J. N. Am. Benthol. Soc. 16: 635-650.

Fujioka, M. and S. J. Lane (1997) The impact of changing irrigation practices in rice fields on frog populations of the Kanto Plain, central Japan. Ecol. Res. 12: 101-108.

Hasegawa, M. (1998) Frog community depending on paddy rice farming. In Conservation of Riparian EnvironmentA Viewpoint from Biological Communities (Y. Esaki and T. Tanaka eds.). Asakura Book Co., Tokyo, pp. 53-66 (in Japanese).

Hibi, N. (1994) Insects sharing irrigation ponds. Nature Insects 29(5): 19-20.

Hidaka, K. (1998) Biodiversity conservation and environmentally regenerated farming system in rice paddy fields. Jpn. J. Ecol. 48: 167-178 (in Japanese).

Hidaka, K. (2000) What's happen in the paddy giant bug. Its conservation and village water sustainability. Nature Insects 35(9): 14-18 (in Japanese).

Hirai, T. and K. Hidaka (2002) Anuran-dependent predation by the giant water bug, Lethocerus deyrollei (Hemiptera: Belostomatidae), in rice fields of Japan. Ecol. Res. 17: 655-661.

Hirai, T. and M. Matsui (2001) Food habit of an endangered Japanese frog, Rana porosa brevipoda. Ecol. Res. 16: 737-743.

Ichikawa, N. (1996) The breeding ecology of giant water bugs. Nature Insects 31(11): 8-11 (in Japanese).

Ichikawa, N. (2004) Rebirth of abundant natural environment around paddy fields and the successful settlement of giant water bugs and other wetland animals. Bull. Hoshizaki Found. 7: 137-150 (in Japanese).

Ishii, M. (2003) Conservation of species. In Kontyu-gaku Daijiten (J. Mitsuhashi ed.). Asakura Book Co., Tokyo, pp. 1087-1102 (in Japanese).

Kadono, Y. (1998) Diversity of the flora of Naka-ikemi, a lowland wetland in Tsuruga, Fukui Prefecture, and significance of its conservation. Jpn. J. Ecol. 48: 163-166 (in Japanese). 
Katano, O. (1998) Fish communities in rice fields and irrigation ditches. In Conservation of Riparian EnvironmentA Viewpoint from Biological Communities (Y. Esaki and T. Tanaka eds.). Asakura Book Co., Tokyo, pp. 67-79 (in Japanese).

Kiritani, K. (2000) Integrated biodiversity management in paddy fields: shift of paradigm from IPM to IBM. Int. Pest Manag. Rev. 5: 175-183.

Lawler, S. P. (2001) Rice fields as temporary wetlands: A review. Israel J. Zool. 47: 512-528.

Lytle, D. A. (1999) Use of rainfall cues by Abedus herberti (Hemiptera: Belostomatidae): a mechanism for avoiding flash floods. J. Insect Behav. 12: 1-12.

Marques, P. A. M. and L. Vicente (1999) Seasonal variation of waterbird prey abundance in the Sado Estuary rice fields. Ardeola 46: 231-234.

Ministry of the Environment of Japan (2006) Threatened Wildlife of Japan-Red Data Book 2nd ed. Vol. 5. Insecta. Japan Wildlife Research Center, Tokyo, p. 246 (in Japanese).

Morisita, M. (1962) $I_{\delta}$-index, a measure of dispersion of individuals. Res. Popul. Ecol. 4: 1-7.

Moriyama, H. (1997) What Is Protecting Paddy Fields? Nobunkyo, Tokyo. 205 pp. (in Japanese).

Mukai, Y., N. Baba and M. Ishii (2005) The water system of traditional rice paddies as an important habitat of the giant water bug, Lethocerus deyrollei (Heteroptera: Belostomatidae). J. Insect Conserv. 9: 121-129.

Ohba, S. and F. Nakasuji (2006) Dietary items of predacious aquatic bugs (Nepoidea: Heteroptera) in Japanese wetlands. Limnology 7: 41-43.

Ohba, S. and H. Takagi (2005) Food shortage affects flight migration of the giant water bug Lethocerus deyrolli in the prewintering season. Limnology 6: 85-90.

Okada, H. and F. Nakasuji (1993a) Comparative studies on the seasonal occurrence, nymphal development and food menu in two giant water bugs, Diplonychus japonicus Vuillefroy and Diplonychus major Esaki (Hemiptera: Belostomatidae). Res. Popul. Ecol. 35: 15-22.

Okada, H. and F. Nakasuji (1993b) Patterns of local distribution and coexistence of two giant water bugs, Diplonychus japonicus Vuillefroy and Diplonychus major Esaki (Hemiptera: Belostomatidae) in Okayama, western Japan. Jpn. J. Entomol. 61: 79-84.

Okada, H., K. Fujisaki and F. Nakasuji (1992) Effects of interspecific competition on development and reproduction in two giant water bugs, Diplonychus japonicus Vuillefroy and Diplonychus major Esaki (Hemiptera: Belostomatidae). Res. Popul. Ecol. 34: 349-358.

Osaka Prefecture (2000) Osaka Red Data Book 2000.3. Osaka Prefecture, p. 221 (in Japanese).

Rice, W. R. (1989) Analyzing tables of statistical tests. Evolution 43: 223-225.

Saijo, H. (2001) Seasonal prevalence and migration of aquatic insects in paddies and an irrigation pond in Shimane Prefecture. Jpn. J. Ecol. 51: 1-11 (in Japanese with English summary).

Saijo, H. (2002) The role of loach-farming paddy on the life cycle of aquatic insects inhabiting lentic habitats. Jpn. J. Ecol. 52: 155-165 (in Japanese with English summary).

Takeuchi, T., R. D. Brown, I. Washitani, A. Tsunekawa and M. Yokohari (2003) Satoyama-The Traditional Rural Landscape of Japan. Springer-Verlag, Tokyo. 229 pp.

Udagawa, T. (1998) What should we do for the conservation of biological diversity in an ago-ecosystem? Res. J. Food Agric. 21(12): 9-14 (in Japanese).

Ueda, T. (1998) Odonata community in paddy fields. In Conservation of Riparian Environment-A Viewpoint from Biological Communities (Y. Esaki and T. Tanaka eds.). Asakura Book Co., Tokyo, pp. 93-110 (in Japanese). 